\title{
Mesogenic benzothiazole derivatives with methoxy substituents ${ }^{+}$
}

\author{
A K PRAJAPATI* and N L BONDE \\ Applied Chemistry Department, Faculty of Technology and Engineering, Kalabhavan, P.O. Box No. 51, \\ MS University of Baroda, Vadodara 390001 \\ e-mail: akprajapati@yahoo.co.uk
}

MS received 8 September 2005; revised 15 December 2005

\begin{abstract}
Two new mesogenic homologous series containing 6-methoxybenzothiazole ring at the terminus of the molecule, viz. 2-(4'-n-alkoxyphenylazo)-6-methoxybenzothiazoles and 2-[4'-(4"'-n-alkoxybenzoyloxy)phenylazo]-6-methoxybenzothiazoles were synthesized. In series I, $n$-butyloxy to $n$-tetradecyloxy derivatives exhibit nematic mesophase. Smectic A mesophase commences from the $n$-dodecyloxy derivative as a monotropic phase and is retained up to the last member synthesized. All the members of series II exhibit enantiotropic nematic mesophase. The mesomorphic properties of the present series are compared with other structurally related series to evaluate the effect of the benzothiazole ring and the methoxy substituent on mesomorphism.
\end{abstract}

Keywords. 6-Methoxybenzothiazole; azomesogens; smectic A; nematic.

\section{Introduction}

The effects of different substituents and their position on mesogenic properties were widely studied by many researchers and the relation between them has been established. ${ }^{1-3}$

Liquid crystals containing heterocyclic moieties have received great attention because of their interesting properties. ${ }^{4}$ The inclusion of a heteroatom can cause large changes in the kind of mesophase present or in the physical properties of the mesophase. Many mesogenic compounds containing heterocyclic rings have been reported in the literature. Single ring heterocylic moieties such as pyridine, ${ }^{5-7}$ furyl, ${ }^{5}$ substituted pyrimidine carboxylic acid, ${ }^{8}$ thiazole, ${ }^{9}$ thiadiazole $\mathrm{e}^{10-13}$ and oxadiazole ${ }^{12}$ are reported in the literature. Barbera et $a l^{14}$ have synthesized 2-pyrazoline derivatives and also studied the optical, NLO and mesogenic properties of such materials. Highly polar thiophene-based liquid crystals have also been reported ${ }^{15}$ in the literature. However, fused ring heterocyclic derivatives which are two condensed rings are practically planar and rigid molecules. Liquid crystals containing fused heterocyclic ring systems such as coumarin ${ }^{16}$ derivatives containing

\footnotetext{
*For correspondence

${ }^{+}$This paper was presented at the 10th National Conference on Liquid Crystals held at Bangalore during 9-11 October 2003
}

azo central linkages, thiazole[5,4- $d]$ thiazoles, ${ }^{17}$ imidazo[2,1- $b]-1,3,4$-thiadiazoles ${ }^{18}$ derivatives, isocoumarin ${ }^{19}$ derivatives having central ester and amide linkages exhibiting smectic $\mathrm{C}$ and nematic mesophase with very high mesophase transition temperatures, esters of 7-decanoyl oxychromone-3-carboxylic acid, ${ }^{20,21}$ flavone ${ }^{22}$ etc. are reported in the literature. Recently Xuelong et $a l^{23}$ synthesized and studied the mesogenic properties of benzo-2,1-3-thiadiazole derivatives.

Pavluchenko et $a l^{24}$ reported mesogens containing benzothiazole and benzoxazole with central linkages and lateral substitution at different positions so as to evaluate the effect of structural changes on mesomorphic properties. They observed that substitution at the sixth position was thermally more stable as compared to that at the fifth position on the benzothiazole ring. They also concluded that 6-substituted benzothiazoles in comparison with their benzoxazole analogs have higher mesophase transition temperatures because of the difference in degree of aromatization of azole cycles, viz. degree of conjugation of heteroatom $p$-electrons with $\pi$-electrons of cycle. Recently, we reported ${ }^{32}$ two mesogenic homologous series containing 6-chlorobenzothiazole ring systems with azo and/or ester central linkage. In order to study more about the effect of benzothiazole ring and methoxy substituent on mesomorphic properties in such systems, we have synthesized two new ex- 
tensive mesogenic homologous series of benzothiazole derivatives containing 6-methoxy substituents.

\section{Experimental}

\subsection{Characterization}

The structures of the compounds were confirmed by FTIR spectroscopy via $\mathrm{KBr}$ pellet, using a Shimadzu IR-408 spectrophotometer. ${ }^{1} \mathrm{H}$ NMR spectra were obtained with a Bruker Dpx 200 spectrometer or Bruker 300, using tetramethylsilane (TMS) as an internal reference standard. The chemical shifts are quoted as $\delta$ (parts per million) downfield from reference. $\mathrm{CDCl}_{3}$ was used as a solvent. The liquid crystalline properties of the mesogens were investigated on Leitz Laborlux 12 POL microscope provided with heating stage. The enthalpies of transitions reported as $\mathrm{J} / \mathrm{g}$ were determined from thermograms obtained on a Universal V3.0G TA instrument adopting rate of $5^{\circ} \mathrm{C} / \mathrm{min}$. The calorimeter was calibrated using pure indium as standard. The purity of the final products was confirmed by thin layer chromatography and microanalysis performed on a Perkin-Elmer series 2400 elemental analyzer.

\subsection{Materials}

4-Hydroxybenzoic acid, 4-methoxybenzoic acid, 1bromoalkanes, thionyl chloride, anhydrous potassium carbonate, sodium nitrite, 4-methoxyaniline, potassium thiocyanate, bromine liquid and phenol etc. were used as received. Column chromatography was done on Acme's Silica Gel (100-200 mesh). Solvents were dried and distilled prior to use.

\subsection{Synthesis}

The synthetic route to series I and II is illustrated in schemes $1 \mathrm{a}$ and $1 \mathrm{~b}$ respectively.

2.3a 2-Amino-6-methoxybenzothiazole [2] was prepared from 4-methoxyaniline [1] by the reported method. ${ }^{25}$ Crystallization from $1: 1$ aqueous ethanol afforded pure yellow needles of [2]. Yield: $64 \%$. M.P. $165^{\circ} \mathrm{C}$ (reported ${ }^{24}$ m.p.: $165-167^{\circ} \mathrm{C}$ ).

\section{$2.3 \mathrm{~b} \quad 2-\left(4^{\prime}-\right.$ Hydroxyphenylazo)-6-methoxybenzothi-} azole [4]: This was synthesized by diazotization of compound [2] and coupling with phenol by follow- ing the method reported by Johari and Varshney. ${ }^{26}$ The dye thus obtained was crystallized several times using alcohol till constant melting point was obtained. Yield: $58 \%$, m.p.: $256^{\circ} \mathrm{C}$. Elemental analysis: found C 58.46, H 3.51, N $14.98 \%, \mathrm{C}_{14} \mathrm{H}_{11} \mathrm{~N}_{3} \mathrm{O}_{2} \mathrm{~S}$ requires $\mathrm{C} 58.93, \mathrm{H} 3.89, \mathrm{~N} 14.73 \%$. The FTIR spectrum showed a broad peak of intermolecularly hydrogen bonded, phenolic $-\mathrm{OH}$ at $3200-3600 \mathrm{~cm}^{-1}$. Other signals observed were at $3051\left(\mathrm{v}_{\mathrm{C}-\mathrm{H}}\right.$, aromatic), 2924 ( $v_{\mathrm{C}-\mathrm{H}}$, aliphatic), 2360, 1600, 1495, 1267 (Ar-O- $\mathrm{CH}_{3}$ ), 1057 (benzothiazole), 1015, 826, 690, 650 (C-S-C) $\mathrm{cm}^{-1}$.

\section{3c 2-(4'-n-Alkoxyphenylazo)-6-methoxybenzothi-} azoles [I]: These were synthesized by alkylation of dye [4] using the reported method of Vyas and Shah. ${ }^{27}$ 2-(4'-Hydroxyphenylazo)-6-methoxybenzothiazole $(0.1 \mathrm{~mol})$, appropriate 1-bromoalkane $(0.12 \mathrm{~mol})$ and anhydrous potassium carbonate $(0.15 \mathrm{~mol})$ were added to dry acetone $(60 \mathrm{ml})$. The reaction mixture was refluxed on a water bath for eight to ten hours. Completion of the reaction was checked by TLC (10\% ethylacetate: hexane). The reaction mixture was added to ice-cold water. The crude solid product thus obtained was triturated with cold 5\% aqueous sodium hydroxide solution for $30 \mathrm{~min}$ so as to remove unreacted azo dye and was washed with water. The product obtained was purified by column chromatography using silica (100200 mesh size) and 3\% ethyl acetate-petroleum ether (60-80) as eluent. The compound obtained was finally crystallized using ethanol. Yield: 54-63\%. The elemental analysis of all the compounds of series I was satisfactory and results are listed in table 1 . IR and ${ }^{1} \mathrm{H}$ NMR spectral data of $n$-decyloxy and $n$ tetradecyloxy derivatives as representative members are given below.

2-(4'-n-Decyloxyphenylazo)-6-methoxybenzothiazoleIR spectrum $(\mathrm{KBr}) \mathrm{v}_{\max } / \mathrm{cm}^{-1}: 3041\left(\mathrm{v}_{\mathrm{C}-\mathrm{H}}\right.$, aromatic), $2922\left(v_{\mathrm{C}-\mathrm{H}}\right.$, aliphatic), 2852, 2370, $1599(-\mathrm{N}=\mathrm{N}-)$, 1489, 1464, 1263 (Ar-O-R), 1056 (benzothiazole), 832, 725, 694, 647 (C-S-C).

${ }^{1} \mathrm{H}$ NMR spectrum $\left(\mathrm{CDCl}_{3}, 200 \mathrm{MHz}\right): \delta 8.00$ $8.04(m, 3 \mathrm{H}$, ArH at C-2' and C-6' and C-4) $7.30(d$, $J_{7,5}=2 \cdot 3 \mathrm{~Hz}, 1 \mathrm{H}, \quad \mathrm{ArH}$ at C-7), $7 \cdot 12\left(d d, J_{5,7}=\right.$ $2.3 \mathrm{~Hz}, J_{5,4}=8.8 \mathrm{~Hz}, 1 \mathrm{H}, \mathrm{ArH}$ at C-5), $7.02(d$, $J=9 \mathrm{~Hz}, 2 \mathrm{H}, \mathrm{ArH}$ at $\mathrm{C}^{-} 3^{\prime}$ and C-5'), $4.07(t, 2 \mathrm{H}, \mathrm{Ar}-$ $\left.\mathrm{O}_{-} \mathrm{CH}_{2^{-}}\right), 3.91\left(s, 3 \mathrm{H}, \mathrm{Ar}-\mathrm{O}-\mathrm{CH}_{3}\right), 1.82(m, 2 \mathrm{H}, \mathrm{Ar}-$ O-C- $\left.\mathrm{CH}_{2}-\right), 1.28-1.58\left(\mathrm{~m}, 14 \mathrm{H}, 7 \mathrm{x}-\mathrm{CH}_{2}-\right), 0.87(t$, $\left.3 \mathrm{H},-\mathrm{CH}_{3}\right)$. 

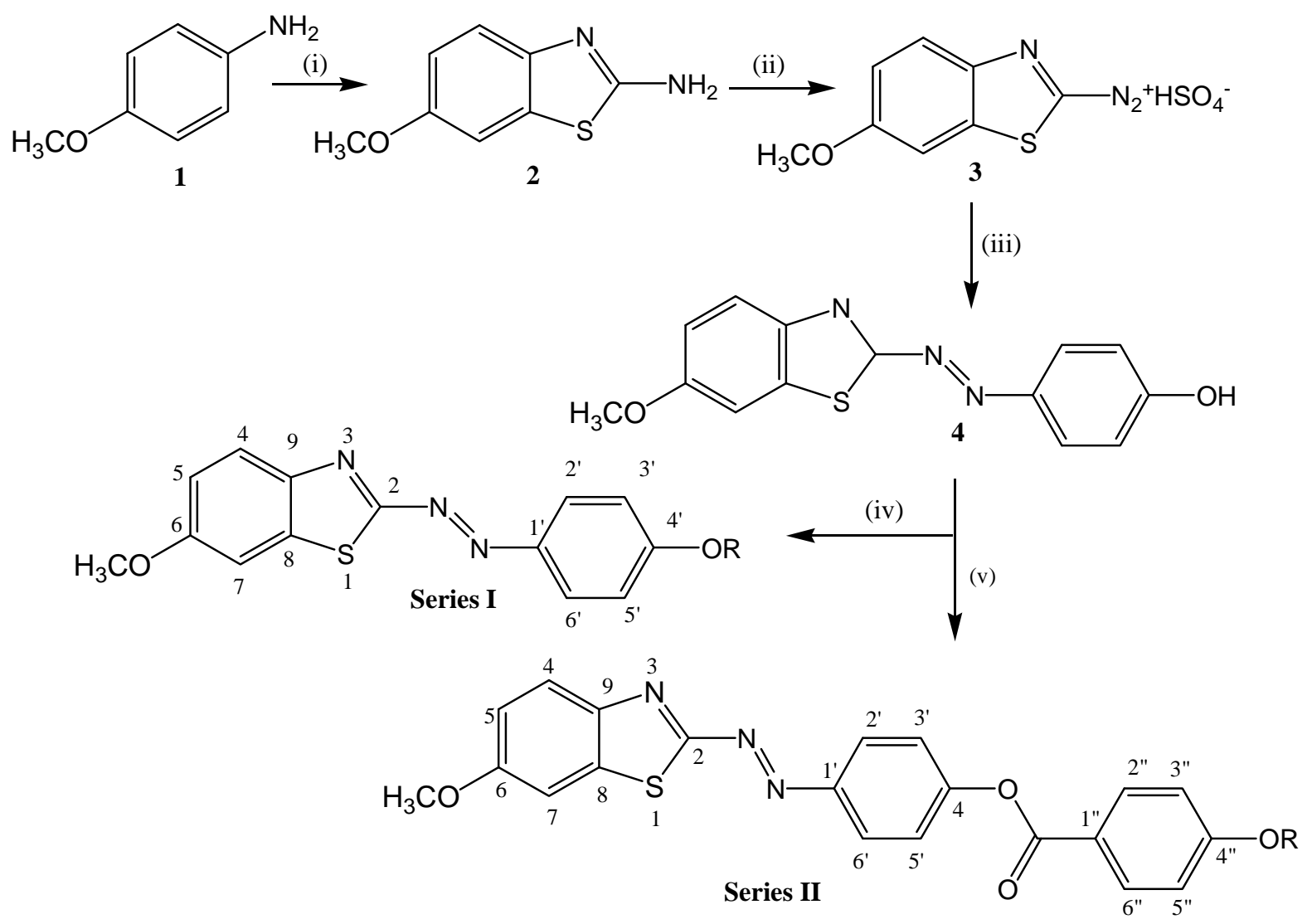

(i) $\mathrm{KSCN}, \mathrm{Br}_{2}, \mathrm{AcOH}$; (ii) $\mathrm{NaNO}_{2}, \mathrm{H}_{2} \mathrm{SO}_{4}, 0-5^{\circ} \mathrm{C}$; (iii) phenol, $10 \% \mathrm{NaOH}$ (aq.), 0-10 ${ }^{\circ} \mathrm{C}$; (iv) $\mathrm{RBr}, \mathrm{K}_{2} \mathrm{CO}_{3}$, acetone; Series I: $\quad \mathrm{R}=-\mathrm{C}_{n} \mathrm{H}_{2 n+1}, n=4-8,10,12$ and 16; (v) 4-n-alkoxybenzoyl chloride, pyridine; Series II: $\mathrm{R}=-\mathrm{C}_{n} \mathrm{H}_{2 n+1}, n=1-8,10,12,14$ and 16 .

Scheme 1. Synthetic route to series I and II.

2-(4'-n-Tetradecyloxyphenylazo)-6-methoxybenzothiazole - IR spectrum $(\mathrm{KBr}) \mathrm{v}_{\max } / \mathrm{cm}^{-1}: 3049\left(\mathrm{v}_{\mathrm{C}-\mathrm{H}}\right.$, aromatic), 2930 ( $\mathrm{v}_{\mathrm{C}-\mathrm{H}}$, aliphatic), 2854, 2369, 1600 $(-\mathrm{N}=\mathrm{N}-), 1493,1467,1262$ (Ar-O-R), 1058 (benzothiazole), 832, 725, 694, 645 (C-S-C).

${ }^{1} \mathrm{H}$ NMR spectrum $\left(\mathrm{CDCl}_{3}, 200 \mathrm{MHz}\right): \delta 8.00-$ $8.03(\mathrm{~m}, 3 \mathrm{H}$, ArH at C-2' and C-6' and C-4) $7.30(d$, $J_{7,5}=2.4 \mathrm{~Hz}, 1 \mathrm{H}, \quad$ ArH at C-7), $7 \cdot 11\left(d d, J_{5,7}=\right.$ $2.4 \mathrm{~Hz}, J_{5,4}=8.7 \mathrm{~Hz}, 1 \mathrm{H}$, ArH at C-5), $7.01(d$, $J=9 \mathrm{~Hz}, 2 \mathrm{H}, \mathrm{ArH}$ at C-3' and C-5'), $4.06(t, 2 \mathrm{H}, \mathrm{Ar}-$ $\left.\mathrm{O}-\mathrm{CH}_{2}-\right), 3.91\left(s, 3 \mathrm{H}, \mathrm{Ar}-\mathrm{O}-\mathrm{CH}_{3}\right), 1.82(m, 2 \mathrm{H}, \mathrm{Ar}-$ O-C- $\left.\mathrm{CH}_{2}-\right), 1.26-1.61\left(\mathrm{~m}, 22 \mathrm{H}, 11 \mathrm{x}-\mathrm{CH}_{2}-\right), 0.88(t$, $\left.3 \mathrm{H},-\mathrm{CH}_{3}\right)$.

2.3d 4-n-Alkoxybenzoic acids and 4-n-alkoxybenzoyl chlorides: These were synthesized by the modified method of Dave and Vora. ${ }^{28}$

$2.3 \mathrm{e}$ 2-[4'-(4"-n-Alkoxybenzoyloxy) phenylazo]-6methoxybenzothiazoles [II]: The compound [4]
(0.02 mol) was dissolved in dry pyridine $(5 \mathrm{ml})$ and a cold solution of 4-n-alkoxybenzoyl chloride $(0.02 \mathrm{~mol})$ in dry pyridine was added with stirring in an ice bath. The mixture was allowed to stand overnight at room temperature. It was acidified with cold $1: 1$ aqueous hydrochloric acid. The solid obtained was separated, dried and triturated by stirring for 30 min with 5\% aqueous sodium hydroxide solution and was washed with water. The insoluble mass separated was recrystallized several times from acetic acid till constant transition temperatures were obtained. Yield $62-70 \%$. The elemental analysis of all compounds of series II was satisfactory and results are listed in table 1. IR and ${ }^{1} \mathrm{H}$ NMR spectral data of $n$-decyloxy and $n$-tetradecyloxy derivatives as representative members are given below.

2-[4'-(4"-n-Decyloxybenzoyloxy) phenylazo]-6-methoxybenzothiazole: IR spectrum $(\mathrm{KBr}) v_{\max } / \mathrm{cm}^{-1}$ : 3077 ( $\mathrm{v}_{\mathrm{C}-\mathrm{H}}$, aromatic), 2918 ( $\mathrm{v}_{\mathrm{C}-\mathrm{H}}$, aliphatic), 2849, 
Table 1. Elemental analysis for series I and II.

\begin{tabular}{|c|c|c|c|c|c|}
\hline \multirow[b]{2}{*}{ Compound } & \multirow{2}{*}{$\begin{array}{c}\mathrm{R}=-\mathrm{C}_{n} \mathrm{H}_{2 n+1} \\
n=\end{array}$} & \multirow[b]{2}{*}{ Formula } & \multicolumn{3}{|c|}{$\%$ Required (\% found) } \\
\hline & & & $\mathrm{C}$ & $\mathrm{H}$ & $\mathrm{N}$ \\
\hline \multicolumn{6}{|l|}{ Series I } \\
\hline 1 & 4 & $\mathrm{C}_{18} \mathrm{H}_{19} \mathrm{~N}_{3} \mathrm{O}_{2} \mathrm{~S}$ & $63 \cdot 32(63 \cdot 16)$ & $05 \cdot 61(5 \cdot 85)$ & $12 \cdot 31(12 \cdot 58)$ \\
\hline 2 & 5 & $\mathrm{C}_{19} \mathrm{H}_{21} \mathrm{~N}_{3} \mathrm{O}_{2} \mathrm{~S}$ & $64 \cdot 20(64 \cdot 45)$ & $05 \cdot 95(6 \cdot 18)$ & $11 \cdot 82(11 \cdot 53)$ \\
\hline 3 & 6 & $\mathrm{C}_{20} \mathrm{H}_{23} \mathrm{~N}_{3} \mathrm{O}_{2} \mathrm{~S}$ & $65 \cdot 01(64 \cdot 76)$ & $06 \cdot 27(6 \cdot 04)$ & $11 \cdot 37(11 \cdot 08)$ \\
\hline 4 & 7 & $\mathrm{C}_{21} \mathrm{H}_{25} \mathrm{~N}_{3} \mathrm{O}_{2} \mathrm{~S}$ & $65 \cdot 77(65 \cdot 32)$ & $06 \cdot 57(6 \cdot 77)$ & $10 \cdot 96(11 \cdot 27)$ \\
\hline 5 & 8 & $\mathrm{C}_{22} \mathrm{H}_{27} \mathrm{~N}_{3} \mathrm{O}_{2} \mathrm{~S}$ & $66 \cdot 47(66 \cdot 33)$ & $06 \cdot 85(7 \cdot 04)$ & $10 \cdot 57(10 \cdot 19)$ \\
\hline 6 & 10 & $\mathrm{C}_{24} \mathrm{H}_{31} \mathrm{~N}_{3} \mathrm{O}_{2} \mathrm{~S}$ & $67 \cdot 73(67 \cdot 61)$ & $07 \cdot 34(7 \cdot 51)$ & $09 \cdot 87(09 \cdot 53)$ \\
\hline 7 & 12 & $\mathrm{C}_{26} \mathrm{H}_{35} \mathrm{~N}_{3} \mathrm{O}_{2} \mathrm{~S}$ & $68 \cdot 84(68 \cdot 72)$ & $07 \cdot 78(7 \cdot 49)$ & $09 \cdot 26(09 \cdot 02)$ \\
\hline 8 & 14 & $\mathrm{C}_{28} \mathrm{H}_{39} \mathrm{~N}_{3} \mathrm{O}_{2} \mathrm{~S}$ & $69 \cdot 82(69 \cdot 71)$ & $08 \cdot 16(8 \cdot 37)$ & $08 \cdot 72(09 \cdot 06)$ \\
\hline 9 & 16 & $\mathrm{C}_{30} \mathrm{H}_{43} \mathrm{~N}_{3} \mathrm{O}_{2} \mathrm{~S}$ & $70 \cdot 69(70 \cdot 91)$ & $08 \cdot 50(8 \cdot 13)$ & $08 \cdot 24(07 \cdot 83)$ \\
\hline \multicolumn{6}{|l|}{ Series II } \\
\hline 1 & 1 & $\mathrm{C}_{22} \mathrm{H}_{17} \mathrm{~N}_{3} \mathrm{O}_{4} \mathrm{~S}$ & $63 \cdot 00(63 \cdot 37)$ & $4 \cdot 09(4 \cdot 31)$ & $10 \cdot 02(9 \cdot 72)$ \\
\hline 2 & 2 & $\mathrm{C}_{23} \mathrm{H}_{19} \mathrm{~N}_{3} \mathrm{O}_{4} \mathrm{~S}$ & $63 \cdot 73(63 \cdot 42)$ & $4 \cdot 42(4 \cdot 25)$ & $9 \cdot 69(9 \cdot 57)$ \\
\hline 3 & 3 & $\mathrm{C}_{24} \mathrm{H}_{21} \mathrm{~N}_{3} \mathrm{O}_{4} \mathrm{~S}$ & $64 \cdot 41(64 \cdot 70)$ & $4 \cdot 73(4 \cdot 57)$ & $9 \cdot 39(9 \cdot 83)$ \\
\hline 4 & 4 & $\mathrm{C}_{25} \mathrm{H}_{23} \mathrm{~N}_{3} \mathrm{O}_{4} \mathrm{~S}$ & $65 \cdot 06(65 \cdot 38)$ & $5 \cdot 02(5 \cdot 44)$ & $9 \cdot 10(9 \cdot 35)$ \\
\hline 5 & 5 & $\mathrm{C}_{26} \mathrm{H}_{25} \mathrm{~N}_{3} \mathrm{O}_{4} \mathrm{~S}$ & $65 \cdot 65(65 \cdot 26)$ & $5 \cdot 30(5 \cdot 73)$ & $8 \cdot 84(8 \cdot 43)$ \\
\hline 6 & 6 & $\mathrm{C}_{27} \mathrm{H}_{27} \mathrm{~N}_{3} \mathrm{O}_{4} \mathrm{~S}$ & $66 \cdot 24(66 \cdot 73)$ & $5 \cdot 56(5 \cdot 20)$ & $8 \cdot 58(8 \cdot 21)$ \\
\hline 7 & 7 & $\mathrm{C}_{28} \mathrm{H}_{29} \mathrm{~N}_{3} \mathrm{O}_{4} \mathrm{~S}$ & $66 \cdot 78(66 \cdot 31)$ & $5 \cdot 80(5 \cdot 98)$ & $8 \cdot 34(8 \cdot 66)$ \\
\hline 8 & 8 & $\mathrm{C}_{29} \mathrm{H}_{31} \mathrm{~N}_{3} \mathrm{O}_{4} \mathrm{~S}$ & $67 \cdot 29(67 \cdot 75)$ & $6 \cdot 04(5 \cdot 71)$ & $8 \cdot 12(8 \cdot 53)$ \\
\hline 9 & 10 & $\mathrm{C}_{31} \mathrm{H}_{35} \mathrm{~N}_{3} \mathrm{O}_{4} \mathrm{~S}$ & $68 \cdot 23(67 \cdot 84)$ & $6 \cdot 46(6 \cdot 74)$ & $7 \cdot 70(8 \cdot 04)$ \\
\hline 10 & 12 & $\mathrm{C}_{33} \mathrm{H}_{39} \mathrm{~N}_{3} \mathrm{O}_{4} \mathrm{~S}$ & $69 \cdot 08(68 \cdot 63)$ & $6 \cdot 85(7 \cdot 23)$ & $7 \cdot 32(6 \cdot 87)$ \\
\hline 11 & 14 & $\mathrm{C}_{35} \mathrm{H}_{43} \mathrm{~N}_{3} \mathrm{O}_{4} \mathrm{~S}$ & $69 \cdot 85(70 \cdot 29)$ & $7 \cdot 20(6 \cdot 93)$ & $6 \cdot 98(7 \cdot 18)$ \\
\hline 12 & 16 & $\mathrm{C}_{37} \mathrm{H}_{47} \mathrm{~N}_{3} \mathrm{O}_{4} \mathrm{~S}$ & $70 \cdot 56(70 \cdot 79)$ & $7 \cdot 52(7 \cdot 85)$ & $6 \cdot 67(6 \cdot 40)$ \\
\hline
\end{tabular}

1719 (-COO-), 1605 (-N=N-), 1554, 1492, 1432, 1261 (Ar-O-CH$), 1057$ (benzothiazole), 845, 653 (C-S-C).

${ }^{1} \mathrm{H}$ NMR spectrum $\left(\mathrm{CDCl}_{3}, 300 \mathrm{MHz}\right): \delta 8 \cdot 04-$ $8 \cdot 18$ ( $m, 5 \mathrm{H}, \mathrm{ArH}$ at C-2", C-6" $, \mathrm{C}-2^{\prime}, \mathrm{C}-6^{\prime}$ and C-4), $7 \cdot 45(d, J=8.8 \mathrm{~Hz}, 2 \mathrm{H}, \mathrm{ArH}$ at C-3' and C-5'), 7.33 $\left(d, J_{7,5}=2 \cdot 3 \mathrm{~Hz}, 1 \mathrm{H}, \mathrm{ArH}\right.$ at C-7), $7 \cdot 13\left(d d, J_{5,7}=\right.$ $2 \cdot 3 \mathrm{~Hz}, J_{5,4}=9 \mathrm{~Hz}, 1 \mathrm{H}, \mathrm{ArH}$ at C-5), $7 \cdot 00(d, J=$ $9 \mathrm{~Hz}, 2 \mathrm{H}, \mathrm{ArH}$ at C-3" and C-5"), 4.06 ( $t, 2 \mathrm{H}, \mathrm{Ar}-\mathrm{O}-$ $\mathrm{CH}_{2-}$ ), 3.92 ( $\left.s, 3 \mathrm{H}, \mathrm{Ar}-\mathrm{O}-\mathrm{CH}_{3}\right), 1.83$ ( $m, 2 \mathrm{H}, \mathrm{Ar}-\mathrm{O}-$ $\left.\mathrm{C}-\mathrm{CH}_{2-}\right), 1.28-1.58\left(m, 14 \mathrm{H}, 7 \mathrm{x}-\mathrm{CH}_{2^{-}}\right), 0.89(t, 3 \mathrm{H}$, $-\mathrm{CH}_{3}$ ).

2-[4'-(4"'-n-Tetradecyloxybenzoyloxy) phenylazo]-6methoxybenzothiazole: IR spectrum (KBr) $\mathrm{v}_{\max } /$ $\mathrm{cm}^{-1}$ : 3078 ( $\mathrm{v}_{\mathrm{C}-\mathrm{H}}$, aromatic), 2919 ( $\mathrm{v}_{\mathrm{C}-\mathrm{H}}$, aliphatic), 2850, 1731 (-COO-), $1606(-\mathrm{N}=\mathrm{N}), 1555,1492$, 1435, 1262 (Ar-O-CH ${ }_{3}$ ), 1062 (benzothiazole), 843, 650 (C-S-C).

${ }^{1} \mathrm{H}$ NMR spectrum $\left(\mathrm{CDCl}_{3}, 300 \mathrm{MHz}\right): \delta 8.05-$ $8 \cdot 17$ ( $m, 5 \mathrm{H}, \mathrm{ArH}$ at C-2", C-6", C-2', C-6' and C-4), $7.43(d, J=8.7 \mathrm{~Hz}, 2 \mathrm{H}, \mathrm{ArH}$ at C-3' and C-5'), 7.33 $\left(d, J_{7,5}=2 \cdot 1 \mathrm{~Hz}, 1 \mathrm{H}, \mathrm{ArH}\right.$ at C-7), $7 \cdot 13\left(d d, J_{5,7}=\right.$ $2 \cdot 1 \mathrm{~Hz}, J_{5,4}=8 \cdot 7,1 \mathrm{H}, \mathrm{ArH}$ at C-5 $), 6 \cdot 93-7 \cdot 0(m, 2 \mathrm{H}$,
ArH at C-3" and C-5"), 3·84-4.08 ( $m, 5 \mathrm{H}, 2 \mathrm{H}$ of Ar$\mathrm{O}-\mathrm{CH}_{2}$ and $3 \mathrm{H}$ of Ar-O-CH ), 1.8-1.85 ( $m, 2 \mathrm{H}, \mathrm{Ar}-$ $\left.\mathrm{O}-\mathrm{C}-\mathrm{CH}_{2}\right), 1 \cdot 27-1.46\left(\mathrm{~m}, 22 \mathrm{H}, 11 \mathrm{x}-\mathrm{CH}_{2}\right), 0.88(t$, $3 \mathrm{H}, \mathrm{CH}_{3}$ ).

\section{Results and discussion}

\subsection{Microscopic observation and DSC for series I and II}

The mesophase exhibited by series I and II compounds is identified by examining the thin film of a sample sandwiched between a glass slide and cover slip. In series I compounds, on cooling the isotropic liquid, small droplets appear which coalesce to marble/schlieren texture characteristic of the nematic phase. On further cooling, the higher members $(n \geq 12)$ show focal conic texture characteristic of SmA mesophase. In all the compounds of series II, on cooling the isotropic liquid, small droplets appeared which coalesce to classical schlieren (threaded) or marble textures characteristic of the nematic phase. Transition temperatures obtained for both the series are recorded in table 2 (enantiotropic phase temperatures are recorded in heating cycle). 
Table 2. Transition temperatures $\left({ }^{\circ} \mathrm{C}\right)$ of the series I and II compounds.

\begin{tabular}{|c|c|c|c|c|c|c|c|c|}
\hline Compound & $\mathrm{R}=-\mathrm{C}_{n} \mathrm{H}_{2 n+1} \quad n=$ & $\mathrm{Cr}$ & & $\operatorname{SmA}$ & & $\mathrm{N}$ & & I \\
\hline \multicolumn{9}{|l|}{ Series I } \\
\hline 1 & 4 & $\bullet$ & 102 & - & & • & 141 & • \\
\hline 2 & 5 & $\bullet$ & 106 & - & & $\bullet$ & 140 & • \\
\hline 3 & 6 & • & 112 & - & & $\bullet$ & 138 & - \\
\hline 4 & 7 & - & 87 & - & & $\bullet$ & 137 & $\bullet$ \\
\hline 5 & 8 & $\bullet$ & 94 & - & & $\bullet$ & 136 & $\bullet$ \\
\hline 6 & 10 & • & 98 & - & & • & 135 & - \\
\hline 7 & 12 & • & 113 & $\bullet$ & $(0 \cdot 108)^{*}$ & $\bullet$ & 135 & - \\
\hline 8 & 14 & • & 105 & - & $(0 \cdot 100)$ & • & 132 & - \\
\hline 9 & 16 & $\bullet$ & 102 & $\bullet$ & $(0.99)$ & $\bullet$ & 118 & • \\
\hline \multicolumn{9}{|l|}{ Series II } \\
\hline 10 & 1 & $\bullet$ & 158 & - & & $\bullet$ & 296 & $\bullet$ \\
\hline 11 & 2 & $\bullet$ & 162 & - & & $\bullet$ & 295 & - \\
\hline 12 & 3 & • & 152 & - & & • & 291 & • \\
\hline 13 & 4 & • & 155 & - & & • & 282 & • \\
\hline 14 & 5 & • & 134 & - & & • & 273 & - \\
\hline 15 & 6 & • & 131 & - & & • & 269 & • \\
\hline 16 & 7 & • & 128 & - & & • & 267 & • \\
\hline 17 & 8 & • & 126 & - & & • & 265 & • \\
\hline 18 & 10 & • & 130 & - & & • & 261 & • \\
\hline 19 & 12 & • & 131 & - & & • & 254 & • \\
\hline 20 & 14 & • & 135 & - & & • & 244 & • \\
\hline 21 & 16 & • & 129 & - & & • & 238 & - \\
\hline
\end{tabular}

( )*Monotropic value; $\mathrm{Cr}$ : crystalline solid phase; Sm A: smectic A phase; N: nematic Phase; I: isotropic liquid phase; •: phase exists; -: phase does not exist

Table 3. DSC data for series I and II compounds.

\begin{tabular}{|c|c|c|c|c|c|}
\hline Series & Compound & Transition & Peak temp. $\left({ }^{\circ} \mathrm{C}\right)$ & $\ddot{\mathrm{A}} H\left(\mathrm{~J} \mathrm{~g}^{-1}\right)$ & $\ddot{\mathrm{A}} S\left(\mathrm{Jg}^{-1} \mathrm{~K}^{-1}\right)$ \\
\hline \multirow[t]{8}{*}{ I } & \multirow[t]{2}{*}{6} & $\mathrm{Cr}-\mathrm{N}$ & $100 \cdot 5$ & $57 \cdot 5$ & $0 \cdot 1539$ \\
\hline & & $N-I$ & $132 \cdot 9$ & $1 \cdot 6$ & $0 \cdot 039$ \\
\hline & \multirow[t]{6}{*}{8} & (Heating cycle) & & & \\
\hline & & $\mathrm{Cr}-\mathrm{N}$ & $105 \cdot 5$ & $59 \cdot 91$ & $0 \cdot 1583$ \\
\hline & & $\begin{array}{c}N-I \\
\text { (Cooling cycle) }\end{array}$ & $130 \cdot 1$ & $1 \cdot 73$ & $0 \cdot 0043$ \\
\hline & & $I-N$ & $129 \cdot 5$ & $1 \cdot 53$ & $0 \cdot 0054$ \\
\hline & & $\mathrm{N}-\mathrm{Sm} A$ & $099 \cdot 3$ & $2 \cdot 19$ & $0 \cdot 1309$ \\
\hline & & $\mathrm{Sm} A-\mathrm{Cr}$ & $093 \cdot 5$ & $48 \cdot 72$ & $0 \cdot 0042$ \\
\hline \multirow[t]{4}{*}{ II } & \multirow[t]{2}{*}{18} & $\mathrm{Cr}-N$ & $130 \cdot 1$ & $75 \cdot 43$ & $0 \cdot 1871$ \\
\hline & & $N-I$ & $260 \cdot 2$ & $1 \cdot 71$ & $0 \cdot 0032$ \\
\hline & \multirow[t]{2}{*}{20} & $\mathrm{Cr}-\mathrm{N}$ & $137 \cdot 6$ & $90 \cdot 1$ & $0 \cdot 2143$ \\
\hline & & $N-I$ & $245 \cdot 0$ & 1.90 & $0 \cdot 0037$ \\
\hline
\end{tabular}

Calorimetry is a valuable method for the detection of phase transition. Conclusions may be drawn concerning the nature of the phases which participate in the transition with the help of calorimetric studies. In the present study enthalpies of two compounds of each series i.e. series I and II were measured by differential scanning calorimetry. Data are recorded in table 3. Enthalpy values of the phase transitions agree well with the existing literature value ${ }^{29}$ which has helped in further confirmation of the mesophase type. 


\subsection{The phase behaviour of series I and II}

3.2a Series I-2-(4'-n-Alkoxyphenylazo)-6-methoxybenzothiazoles: Nine homologues have been synthesized. n-Butyloxy to $n$-decyloxy derivatives exhibit an enantiotropic nematic mesophase. nDodecyloxy to $n$-hexadecyloxy derivatives exhibit polymorphism, as these members shows nematic and monotropic smectic A mesophases. The transition temperatures are recorded in table 2. It is clear from the plot of transition temperatures against the number of carbon atom in the alkoxy chain (figure 1) that the $N-I$ transition shows falling tendency with increase in the chain length. SmA- $N$ transition shows steep falling tendency as the series ascended.

3.2b Series II-2-[4'-(4"-n-Alkoxybenzoyloxy)phenylazo]-6-methoxybenzothiazoles: All the twelve members synthesized exhibit enantiotropic nematic mesophases. The transition temperatures are recorded in table 2. It can be noticed from the plot of

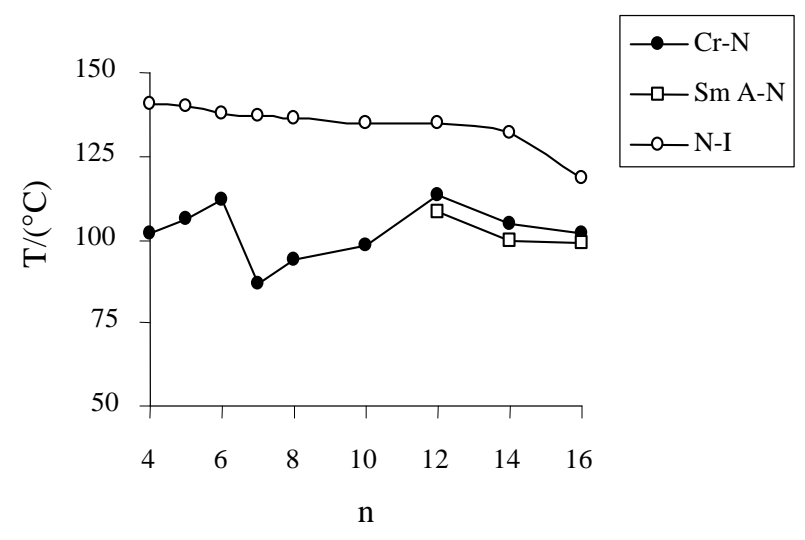

Figure 1. The phase behaviour of series I.

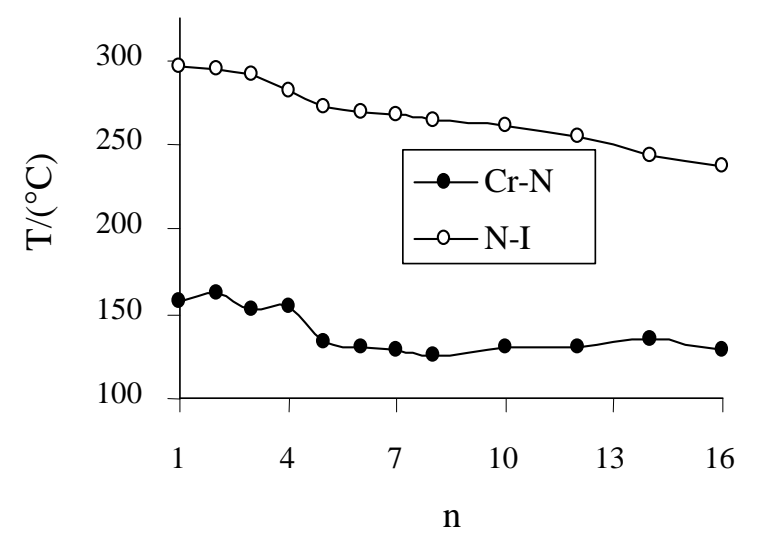

Figure 2. The phase behaviour of series II. transition temperatures against the number of carbon atoms in the alkoxy chain (figure 2) that $N-I$ transition temperatures exhibit a falling tendency with increase in terminal alkoxy tail. This is in agreement with the observation reported for such homologous series. $^{30}$

\subsection{Mesogenic properties and molecular constitution}

There is close relation between mesomorphism and molecular constitution of organic compounds. Hence, transition temperature and mesophase length, measures of mesomorphism can be correlated with the molecular constitution of the compounds.

Table 4 shows the comparison of transition temperatures, range (width) of mesophase phase and thermal stabilities and molecular structures of representative compounds $7(n=12)$ and $19(n=12)$ of the present series I and II with other structurally related compounds $\mathbf{A}^{31}, \mathbf{B}^{32}, \mathbf{C}^{31}$ and $\mathbf{D}^{32}$ reported in the literature. Both compounds $\mathbf{7}$ and $\mathbf{1 9}$ exhibit enantiotropic nematic mesophases. Mesophasic length and nematic thermal stability of compound $\mathbf{1 9}$ are higher by $101^{\circ} \mathrm{C}$ and $119^{\circ} \mathrm{C}$ respectively than that of 7. This is because of the greater length of compound 19 provided by the additional aromatic ring and ester linkage.

Table 4 shows that compound $\mathbf{A}$ is non-mesogenic, whereas compound $\mathbf{7}$ is mesogenic and exhibits enantiotropic nematic and monotropic SmA mesophases. Reference to molecular structure shows that compound A differs only at one terminus. Compound 7 has a 6-methoxy benzothiazole ring at the terminus instead of the naphthalene ring of compound A. Presence of the terminal benzothiazole ring increases the overall polarizability of the molecule while lowering the symmetry of the molecule as compared to phenyl/naphthyl derivatives and provides higher transition temperature. ${ }^{24}$

Table 4 further shows that compound $\mathbf{1 9}$ is purely nematogenic. Nematic mesophase length and nematic phase thermal stability of compound $\mathbf{1 9}$ are higher by $55^{\circ} \mathrm{C}$ and $53^{\circ} \mathrm{C}$ respectively than that of compound C. Both the compounds differ only at one terminus. The absence of smectic mesophase in compound 19 may be due to the methoxy substituent, which diminishes the smectic mesophase. However, the higher mesophase thermal stability of compound 19 compared to compound $\mathbf{C}$ may be because of the terminal benzothiazole ring system. ${ }^{24}$ 
Table 4. The transition temperatures $\left({ }^{\circ} \mathrm{C}\right)$, the mesophase range and molecular structure of compounds $\mathbf{7}, \mathbf{1 9}, \mathbf{A}, \mathbf{B}, \mathbf{C}$ and $\mathbf{D}$.
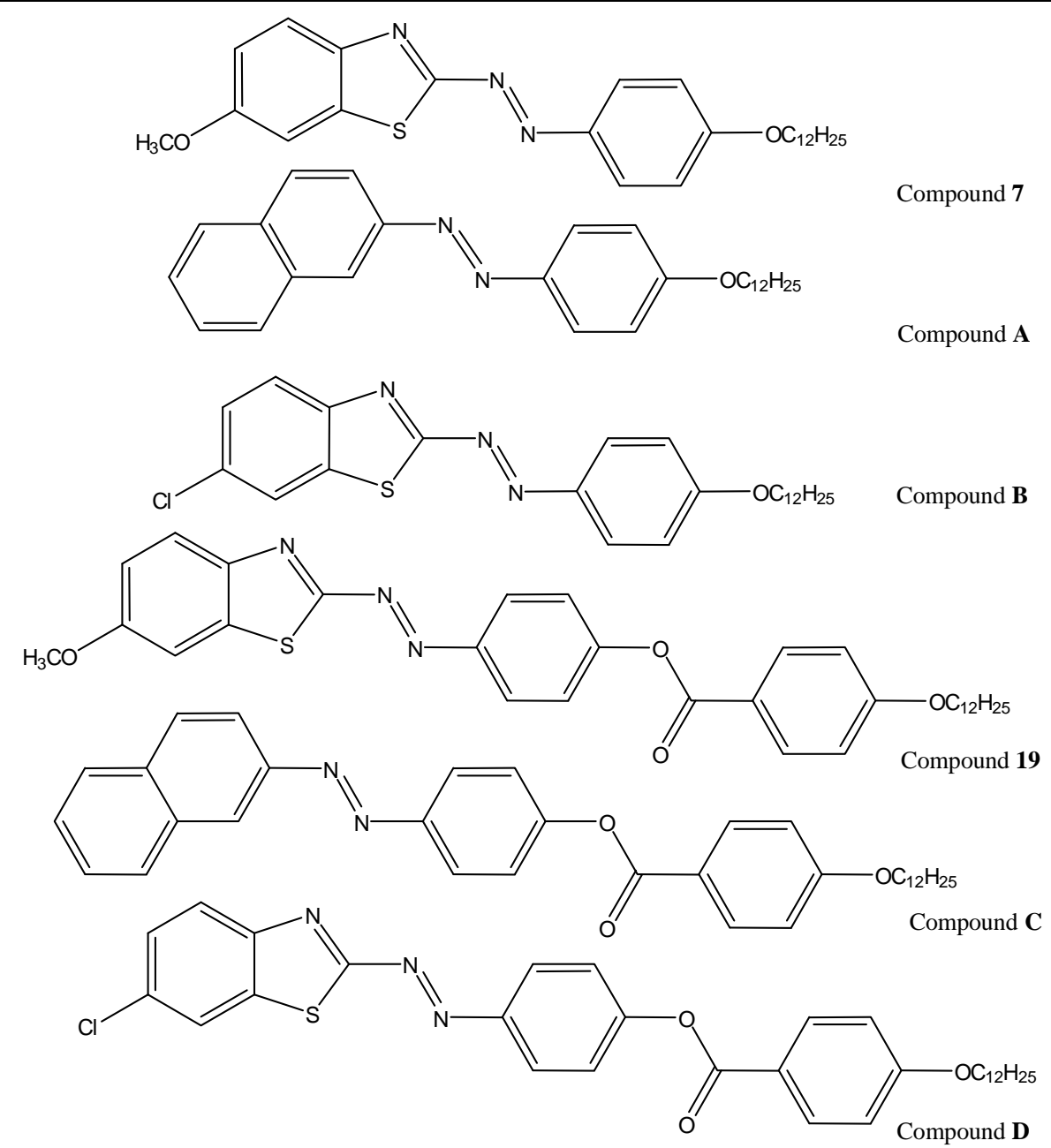

\begin{tabular}{|c|c|c|c|c|c|c|c|c|c|c|}
\hline \multirow[b]{2}{*}{ Compound } & \multicolumn{7}{|c|}{ Transition temperatures $\left({ }^{\circ} \mathrm{C}\right)$} & \multicolumn{2}{|c|}{ Mesophase length } & \multirow{2}{*}{$\begin{array}{l}\text { Commencement } \\
\text { of smectic phase }\end{array}$} \\
\hline & $\mathrm{Cr}$ & & $\mathrm{Sm}$ & & $\mathrm{N}$ & & I & $\mathrm{N}$ & $\mathrm{Sm}$ & \\
\hline 7 & $\bullet$ & 113 & - & $(108)^{*}$ & • & 135 & $\bullet$ & 22 & 7 & $\mathrm{C}_{12}$ \\
\hline $\mathbf{A}$ & $\bullet$ & - & - & - & - & 94 & • & - & - & - \\
\hline B & $\bullet$ & 80 & - & - & - & 172 & & - & 92 & $\mathrm{C}_{5}$ \\
\hline 19 & - & 131 & - & & $\bullet$ & 254 & $\bullet$ & 123 & - & - \\
\hline $\mathbf{C}$ & & (112) & $\bullet$ & 133 & $\bullet$ & 201 & $\bullet$ & 68 & 23 & $\mathrm{C}_{8}$ \\
\hline D & • & 115 & • & 264 & $\bullet$ & 268 & • & 4 & 149 & $\mathrm{C}_{1}$ \\
\hline
\end{tabular}

( )*Monotropic value

Table 4 also shows that the compound 7 exhibit enantiotropic nematic mesophase along with monotropic SmA mesophase, whereas compound $\mathbf{B}$ exhibits enantiotropic SmA mesophase. The smectic mesophase length and smectic thermal stability of compound $\mathrm{B}$ is higher by $85^{\circ} \mathrm{C}$ and $64^{\circ} \mathrm{C}$ respectively than compound 7. These may be because of the presence of the more polar $-\mathrm{Cl}$ group at the sixth position in compound $\mathbf{B}$ as compared to the less polar $-\mathrm{OCH}_{3}$ group at the same position in compound 7 . The more polar $-\mathrm{Cl}$ group increases the molecular polarizability and possibly also the molecular dipo- 
larity of compound B compared to compound 7 . This is also seen in the comparison between compound 19 with compound $\mathbf{D}$.

\section{Conclusions}

Liquid crystalline properties depend on the molecular structure. However, if a specific type of liquid crystal phase is required to exist over a particular range of temperature, then molecular structure should be carefully designed. To obtain compound, showing the nematic mesophase with good mesophase lengths and higher phase transitions, we have synthesized two new mesogenic homologous series with 6-methoxybenzothiazole ring at the terminus. Compounds of series I exhibit low temperature nematic mesophases as compared to those of series II, except that the last three members of series I exhibit smectic mesophase, whereas series II is purely nematogenic.

By comparing the present series with other structurally related series it is found that the benzothiazole ring effects greatly the mesophase thermal stability. The study also shows that a methoxy substituent positions of the benzothiazole ring favours the formation of the nematic mesophase.

\section{Acknowledgements}

The authors thank Prof S M Joshi, Faculty of Technology and Engineering and Dr C N Murthy, Applied Chemistry Department for encouragement. One of the authors (NB) thanks the MS University of Baroda for a University Research Scholarship.

\section{References}

1. Filippov S K, Kolomiets I P, Sokolova O S, Antonov E, Zorin A and Bilibin Y 1998 Liq. Cryst. 24787

2. Neubert M E, Keast S S, Dixon-Polverine Y, Herlinger F, Jirousek M R, Leung K, Murray K and Rambler J 1994 Mol. Cryst. Liq. Cryst. Sci. Technol. A250 109

3. Bezborodov V and Lapanik V 1997 Mol. Cryst. Liq. Cryst. Sci. Technol. A302 315

4. Parra M, Alderete J, Zuniga C, Gallardo H, Hindalgo P, Veragara J and Hernandez S 2001 Liq. Cryst. 28 1659 , and references therein

5. Karda D, Mieczkowski J, Pociecha D, Szydloska J and Gorcecka E 2001 J. Mater. Chem. 11741

6. Champa R A 1973 Mol. Cryst. Liq. Cryst. 19233

7. Dave J S and Menon M 2000 Bull. Mater. Sci. 23237
8. Milkhaleva M A 2003 Chem. Heterocycl. Comp. 39 1032

9. Lee C and Yamamoto T 2001 Mol. Cryst. Liq. Cryst. 36995

10. Dimitrowa K, Hauschild J, Zaschke H and Shubert H 1980 J. Prakt. Chem. 322933

11. Schafer W, Rosenfeld U, Zaschke H, Stettin H and Kresse H 1989 J. Pract. Chem. 321631

12. Parra M, Alderete J, Zuniga C, Gallardo H, Hidalgo P, Veragara J and Hernandez S 2000 Liq. Cryst. 27 995

13. Parra M, Vergara J, Alderete J and Zuniga C 2004 Liq. Cryst. 311531

14. Barbera J, Clays K, Giménez R, Houbrechts S, Persoonsb A and Serrano J L 1998 J. Mater. Chem. 8 1725

15. Wu L-W, Wang Y and Hsu C-H 2000 Liq. Cryst. 27 1503

16. Chudgar N K, Parekh M K, Madhavrao S S and Sharma H C 1995 Liq. Cryst. 19807

17. Bartulin J and Zuniga C 1990 Mol. Cryst. Liq. Cryst. 180297

18. Filippov S K, Kolomiets I P, Sokolova O S, Antonov E A, Zorian I M and Bilibin Y 1998 Liq. Cryst. 24 787

19. Purohit N V and Methus E 2000 J. Inst. Chem. (India) 7277

20. Alderete J, Belmar J, Parra M, Zuniga C and Jimenez V 2003 Liq. Cryst. 301319

21. Belmar J, Parra M, Zuniga C, Fuentes G, Macros M and Serrano J L 1999 Liq. Cryst. 269

22. Hirose T, Tsuya K, Nishigaki T, Idaka E and Yano S 1989 Liq. Cryst. 4653

23. Xuelong Z, Hideki G, Masami K, Takako K, Tsutomu I, Thies T and Shunataro M 2004 J. Mater. Chem. 141901

24. Pavluchenko A I, Smirnova N I, Titov V V, Kovahev E I and Djumaev K M 1976 Mol. Cryst. Liq. Cryst. 37

25. Matsui M, Kamino Y, Hayashi M, Funabiki K, Shibata K, Muramatsu H and Kaneko M 1998 Liq. Cryst. 25235

26. Johri S and Varshney A 1996 J. Chem. Soc. 73629

27. Vyas G M and Shah N M 1963 Organic synthesis collected Volume IV (Rev. edn Ann. Vol. 30-39) (New York: John Wiley and Sons) p. 826

28. Dave J S and Vora R A 1970 Liquid crystals and ordered fluids (eds) J F Johnson and R S Porter (New York: Plenum) p. 477

29. Marzotko D and Demus D 1975 Pramana 1189

30. Demus D, Goodby J, Gray G W and Spiess H-W 1998 Handbook of liquid crystals (Wiley-VCH Verlag) vol. 1, p. 147

31. Vora R A and Prajapati A K 1996 Proc. of the 4th National Seminar of Liquid Crystals, Patiala, p. 97

32. Prajapati A K and Bonde N 2005 Proc. of 11th National Conference on Liquid Crystals, Allahabad, p. 114 